\title{
Infecção pelo Papiloma Vírus Humano (HPV): incertezas e desafios
}

\author{
Infection by Human Papilomavirus (HPV): doubts and challenges \\ Infección por el Virus Papiloma Humano (HPV):inseguridad y desafios
}

\author{
Danielle Teixeira Queiroz¹, Sarah Maria Fraxe Pessoa², Rosiléa Alves de Sousa ${ }^{3}$
}

\begin{abstract}
RESUMO:Trata-se de um estudo com mulheres portadoras de HPV, que busca identificar o nível de conhecimento, os sentimentos e as expectativas das mulheres portadoras de HPV frente ao diagnóstico da doença e a interferência da patologia nas relações conjugais. Pesquisa exploratória, realizado no Centro de Treinamento em Atenção Primária situado na Escola de Saúde Pública do Ceará. Foram entrevistadas 20 mulheres com diagnóstico de HPV. A análise das falas referentes ao nível de conhecimento da doença e as formas de prevenção revelaram que todas as mulheres portadoras do HPV tinham consciência da forma de transmissão e da gravidade da doença. Foram analisados os sentimentos vivenciados frente à descoberta da patologia e à mudança no relacionamento após o diagnóstico da doença, havendo-se construído duas temáticas: A primeira referente às reações emocionais, de onde emergiram as categorias: 1) medo e preocupação; 2) tristeza e impotência diante da cura; 3) surpresa; 4) traição, culpa, raiva e 5) indiferença diante dos resultados; e a segunda relativa às repercussões no relacionamento que permitiram a distribuição nas categorias: 1) descontinuidade da relação com mudança de atitude do casal, 2) separação, 3) sem interferência na relação e 4) negação diante da doença. Consideramos que o nível de conhecimento, os sentimentos e as expectativas das mulheres revelados neste estudo reforçam que abordar as DST nos últimos anos tem sido um desafio para os profissionais de saúde. Muito há de se fazer para alcançar uma mudança de comportamento social que garanta o exercício de uma sexualidade segura
\end{abstract}

Descritores: Papillomavirus humano; Doenças sexualmente transmissíveis; Casamento

ABSTRACT: This is a study with women bearers of HPV, which aims to identify the knowledge level, the feelings and the expectations of the women bearers of HPV front to the diagnosis of the disease and the interference of the pathology in the matrimonial relationships. It is an exploratory research, conducted in the Centro de Treinamento em Atenção Primária placed at the Escola de Saúde Pública do Ceará. Twenty women with diagnosis of HPV were interviewed. The analysis of the speeches regarding the level of knowledge of the disease and the forms of prevention revealed that all the women bearers of HPV were aware of the way of transmission and of the gravity of the disease. One analyzed the feelings experienced due to the discovery of the pathology and the change in the relationship after the diagnosis of the disease, and two themes were built: the first regarding the emotional reactions, from where the following categories emerged: 1) fear and concern; 2) sadness and impotence before the cure; 3) surprise; 4) betrayal, blames, rage and 5) indifference before the results; and the second regarding the repercussions in the relationship that allowed the distribution in the categories: 1) discontinuance of the relationship with change in the attitude of the couple, 2) separation, without 3) interference in the relationship and 4) denial before the disease. We considered that the knowledge level, the feelings and the women's expectations revealed in this study reinforce that to approach DST in the last years has been a challenge for the health professionals. There is much to do in order to reach a change of social behavior that guarantees the exercise of a safe sexuality.

Keywords: Papillomavirus, human; Sexually transmited diseases; Marriage

RESUMEN: Se trata de un estudio con mujeres portadoras de HPV, que busca identificar el nivel de conocimiento, los sentimientos y las expectativas de las mujeres portadoras de VPH frente al diagnóstico de la enfermedad y la interferencia de la patología en las relaciones conyugales. Investigación de tipo exploratória, realizado en el Centro de Entrenamiento en Atención Primaria, situado en la Escuela de Salud Pública de Ceará. Fueron entrevistados 20 mujeres con diagnóstico de VPH. El análisis de las hablas referentes al nivel de conocimiento de la enfermedad y las formas de prevención revelaron que todas las mujeres portadoras del VPH tenían conciencia de la forma de transmisión y de la gravedad de la enfermedad. Fueron analizados los sentimientos existentes frente al descubrimiento de la patología y al cambio en la relación después del diagnóstico de la enfermedad, habiéndose construido dos temáticas: La primera referente a las reacciones emocionales, de donde emergieron las categorías: 1) miedo y preocupación; 2) tristeza e impotencia delante de la cura; 3) sorpresa; 4) traición, culpa, rabia y 5) indiferencia delante de los resultados; y la segunda relativa a las repercusiones en la relación que permitieron la distribución en las categorías: 1) discontinuidad de la relación con cambio de actitud de la pareja, 2) separación, sin 3) interferencia en la relación y 4) negación delante de la enfermedad. Consideramos que el nivel de conocimiento, los sentimientos y las expectativas de las mujeres revelados en este estudio refuerzan que abordar las Enfermedades de Transmisión Sexual (ETS) en los últimos años ha sido un desafío para los profesionales de salud. Mucho hay de hacerse para alcanzar un cambio de comportamiento social que garantice el ejercicio de una sexualidad segura.

Descriptores: Papillomavirus humano; Enfermedades sexualmente transmisibles; Matrimonio

\footnotetext{
1 Enfermeira, Especialista em Saúde da Família, Preceptora de Enfermagem da Residência de Saúde da Família da Escola de Saúde Pública do Ceará, Enfermeira Assistencial do Centro de Saúde PIOXII da Prefeitura Municipal de Fortaleza-CE. E-mail: danizinhatqc@bol.com.br

2 Mestre em Enfermagem Clínico-cirúrgica, Enfermeira da Maternidade Escola Assis Chateaubriand.

3 Doutora em Enfermagem, Enfermeira da Maternidade Escola Assis Chateaubriand
} 


\section{INTRODUÇÃO}

O HPV é um vírus não cultivável do grupo papilomavírus. As alterações celulares desenvolvidas por este vírus foram estudadas, inicialmente em 1956, pelos citologistas Koss e Meisels, que as denominaram de displasias leves, moderadas ou acentuadas, atualmente denominadas de NIC I, NIC II e NIC III ${ }^{(1)}$.

O HPV é a doença sexualmente transmissível (DST) mais prevalente em todo o mundo. Estima-se que, mundialmente, cerca de quinhentas mil a um milhão de pessoas se infectam pelo HPV. No Brasil, existem de três a seis milhões de homens infectados por este vírus ${ }^{(2)}$.

Aproximadamente de 3 a 5\% da população sexualmente ativa brasileira apresentam a doença HPV induzida, isto é, o vírus não se equilibrou com o hospedeiro ou não se apresentou devidamente ao sistema imunológico do portador, levando à manifestação da doença. O laboratório tem nesse momento papel primordial, sobretudo no screening populacional realizado pela colpocitologia oncótica $^{(1)}$.

Desde 1977, quando alguns autores ${ }^{(3)}$ observaram a correlação da infecção pelo HPV com a carcinogênese genital, inúmeros estudos e pesquisas se iniciaram e continuam até os dias atuais. Os estudos tem comprovado que a integração do genoma de determinados tipos de HPV (principalmente os do tipo 16, 18, 31, $33 \mathrm{e}$ 35 ,dentre outras centenas identificadas), com o genoma da célula hospedeira, sobretudo a célula metaplásica cervical, dependendo de outros co-fatores, podem levar à formação de lesões pré-neoplásicas .

O exame de prevenção de câncer ginecológico é uma estratégia para redução dos altos índices de mortalidade por câncer de colo uterino, vagina e vulva causados pelo HPV. Esta estratégia deve ser priorizada pelas políticas de Saúde Pública nos serviços de referência em atenção primária do país.

O aumento da detecção do HPV na última década chegou a $500 \%$. Este fato pode ter sido ocasionado por avanços e descobertas dos aspectos citológicos e histológicos e pela reinterpretação das imagens da colposcopia e da peniscopia. Com o método da Biologia Molecular, tornou-se possível detectar a tipagem do vírus encontrado em tecidos, secreções e fluidos ${ }^{(1)}$.

A partir de dados coletados na Secretaria de Saúde do Estado do Ceará (SESA), verificou-se um aumento progressivo na incidência de casos de HPV, seja na forma subclínica ou através de verrugas anogenitais. No ano de 1995, o número de casos de verrugas genitais foi de 210, enquanto que no ano de 1997 este indicador cresceu para 690. Já o número de casos de infecção subclínica, no ano de 1999 , foi de 325 , enquanto que em 2.002 subiu para 988 casos. Dados recentes demonstram que, do ano de 1995 até agosto de 2002, foram notificados 4.440 casos de HPV nas duas formas há pouco mencionadas ${ }^{(4)}$.

A promoção do diagnóstico precoce da infecção pelo HPV, importante ação para o controle da transmissão, pode ser conseguida por meio de um trabalho eficaz por parte da enfermagem, no que diz respeito à constante informação para a população em geral. Para tanto, são necessárias atividades de educação em saúde e/ou aconselhamento, capazes de proporcionar a percepção dos fatores de riscos associados, especialmente os relacionados ao comportamento sexual, que influencia diretamente na adesão do(a) cliente ao tratamento.

Essa questão surge quando a mulher toma conhecimento da infecção pelo HPV, fazendo-a buscar informações acerca dessa doença e auxiliando a disseminar os modos de prevenção entre as pessoas de seu relacionamento cotidiano ${ }^{(1)}$.

Ao considerar a alta prevalência de casos no Estado e a nossa prática como profissionais responsáveis pela capacitação dos enfermeiros discentes do Curso de Residência Médica e de Enfermagem em Saúde da Família, entendemos como oportuno identificar o nível de conhecimento, os sentimentos e as expectativas das mulheres portadoras de HPV frente ao diagnóstico da doença e a interferência da patologia nas relações conjugais.

Acreditamos na relevância deste estudo, uma vez que pode representar um subsidio para uma assistência humanizada com ênfase nas necessidades de cada cliente.

\section{METODOLOGIA}

Estudo de caráter exploratório ${ }^{(5)}$, que tem como objetivo proporcionar visão geral, de tipo aproximativo, acerca de determinado fato.

O ensaio realizou-se no ambulatório de ginecologia do Centro de Treinamento em Atenção Primária (CTAP) um dos anexos do Centro de Saúde Escola Meirelles, onde funciona a Residência em Saúde da Família Médica e de Enfermagem, localizada na Escola de Saúde Pública do Ceará.

As informantes do estudo foram 40 mulheres atendidas pelos discentes do referido curso, durante o ano de 2004. A pesquisa nos prontuários revelou que 20 mulheres atendiam aos critérios pré-estabelecidos, quais sejam: mulheres com vida sexual ativa, com parceiro fixo ou não e que estejam em acompanhamento no referido serviço.

A coleta de dados foi dividida em três etapas: a primeira das quais constou da preparação de um ofício solicitando permissão da Instituição onde foi realizado o estudo e ao Comitê de Ética para a execução da pesquisa.

A fase seguinte, que ocorreu após a aprovação da Instituição e do Colegiado ora mencionados, foi caracte- 
rizada por um contato inicial com os atores sociais que, devidamente esclarecidos sobre a pesquisa e a garantia do anonimato e sigilo acerca da participação no estudo, assinaram um termo de consentimento livre e esclarecido.

Em seguida, iniciou-se a última fase com a entrevista semi-estruturada, baseada em um roteiro com quatro perguntas:

1. O que é HPV e como se transmite?

2. Você sabe como podemos prevenir a transmissão do HPV?

3. O que você sentiu quando descobriu que estava com HPV?

4. Após o diagnóstico do HPV, como ficou seu relacionamento com seu parceiro?

A entrevista foi gravada, após o consentimento dos sujeitos.

A abordagem deste tipo de entrevista contribui para o aprofundamento de uma relação intersubjetiva do entrevistado com o entrevistador. A inter-relação no ato da entrevista contempla o afetivo, o existencial, o contexto do dia-a-dia, as experiências e a linguagem do senso comum, sendo condição sine qua non para o êxito da pesquisa qualitativa, fatores condizentes com os objetivos da busca ${ }^{(6)}$.

Para garantir a anonimato, substituimos os nomes reais das informantes do estudo pelas denominações de flores, como uma forma carinhosa de agradecimento pela docilidade com que nos forneceram os relatos vividos no período da descoberta da patologia em estudo.

A análise foi realizada mediante a categorização dos conteúdos das falas após a leitura exaustiva das entrevistas. A análise de conteúdo(7), é uma técnica que consiste em apurar descrições de conteúdo muito aproximadas e subjetivas, agregadas em uma temática comum, com a finalidade de pôr em evidência, com objetividade, a natureza e as forças relativas dos estímulos a que o sujeito é submetido.

Após a transcrição das falas, a aproximação dos significados dos discursos nos levou a construção de duas temáticas: reações emocionais e repercussões no relacionamento. Da primeira temática, emergiram cinco categorias: o medo e a preocupação; tristeza e impotência diante da cura; surpresa; traição, culpa, raiva; e indiferença diante do resultado. A segunda temática permitiu a distribuição dos depoimentos em quatro categorias: descontinuidade da relação com mudança de atitude do casal; separação; sem interferência na relação; e negação.

\section{RESULTADOS}

A exploração das falas referentes ao nível de conhecimento das mulheres nos revelou que todas tinham consciência da gravidade e da forma de transmissão da doença conforme vemos a seguir:

Esqueci o que é. Transmite pelo sexo, através do sexo (Buganvília).

Deixa eu me lembrar, uma doença sexual. Transmite pelo sexo (Magnólia).

É uma DST. Se pega com con-tato sexual e outras formas também, objetos pessoais e outros (Papoula).

É um vírus desconhecido que causa medo. É causado sexualmente (Dália).

Um vírus que se acumula dentro da pessoa e se não tratada vira câncer. Causado sexualmente (Rosa Vermelha).

Parece-nos claro que este nível de conhecimento já revela a importância do trabalho de educação em saúde.

Constatamos também com os depoimentos que as mulheres reconhecem o uso do preservativo como melhor estratégia de prevenção:

Tanto fazer a prevenção de ano em ano e usando camisinha (Orvalho).

Usar camisinha e ir ao médico (Hortência).

É importante ressaltar um achado revelador no estudo: mesmo consciente do modo de prevenção, a cliente relatou não fazer uso deste artifício, o que comprova as dificuldades e barreiras nas mudanças comportamentais no que diz respeito ao sexo. Isto fica evidente na fala a seguir:

...Usando camisinha, mas a gente não usa (Cravo).

É importante enfatizar que a mulher mesmo, sabendo que o uso do preservativo é necessário como prérequisito para o tratamento, e percebe esta prática como uma condição que precisa aceitar, apesar de considerála um elemento incômodo que dificulta a vivência da sexualidade do casal.

Os motivos para a não-adesão à "camisinha" vão desde a idéia de que a contaminação só ocorre com os outros, passam pela falta de informação, pela diminuição da auto-estima, pelo descaso com o auto-cuidado das pessoas, pela falta de autonomia ou mesmo pela vergonha e pelo medo de se expor a uma situação embaraçosa em função do uso do preservativo ${ }^{(1)}$. 
A análise das falas nos levou a construir duas temáticas:

1. reações emocionais e

2. repercussões no relacionamento.

\section{Reações Emocionais}

Nesta temática, encontramos quatro categorias:

1. o medo e a preocupação;

2. tristeza e impotência diante da cura;

3. surpresa;

4. traição, culpa, raiva; e

5. indiferença diante do resultado.

\section{Medo e preocupação}

O medo de não ficar curada é evidenciado não somente na fase diagnóstica, mas também durante o tratamento, nos casos em que o progresso é lento. O medo ainda de ter contraído AIDS, uma doença de alta morbidade e letalidade e a mais divulgada das DST's atualmente, povoa o imaginário da mulher portadora do HPV.

Quando informadas de que alguns tipos de HPV têm implicações na gênese do câncer de colo uterino, o medo é um sentimento dominante, revelando o fantasma do câncer como uma força destruidora, uma doença invasiva e silenciosa.

O medo do prejulgamento dos indivíduos e da descoberta da família, gera no portador dificuldades de compartilhar o sofrimento com familiares e amigos ${ }^{(8)}$.

Para muitos, o medo é a emoção negativa mais comum. Mais do que isso: é um dos mais fortes delineadores da personalidade das pessoas, influenciando no que pensamos poder ou não fazer ${ }^{(9)}$.

A reação do parceiro é motivo para preocupação ainda, visto que, ao conhecer que o HPV é uma doença de transmissão sexual, a questão da fidelidade aflora o pensamento humano, tornando-se imprescindível o diálogo e o questionamento da conduta sexual. As falas seguintes evidenciam tais aspectos:

Foi um terror, passei vários dias pensando nisso pensava noite e dia, não conseguia nem dormir com medo de já estar com câncer... (Hortência).

..., será que ele me transmitiu outras doenças, tenho medo de fazer exame e descobrir que tenho AIDS. (Girassol).

As mulheres que tiveram parceiros anteriores aos maridos ou que cometeram adultério sentem-se inseguras quanto às pessoas que as contaminaram ou se elas próprias contaminaram os atuais maridos.

A mulher vê a doença como um castigo ou punição por ter cometido adultério.

\section{Tristeza e impotência diante da cura}

Ser portadora do HPV é também conviver com a dúvida, quando se discute sobre a evolução da doença, pois não é possível dar um prognóstico exato da patologia.

A mulher encontra-se em maior grau de vulnerabilidade, não apenas biológica, mas também em razão de fatores socioeconômicos. A tristeza é manifestada pela possibilidade de recidiva. As falas a seguir demonstram tais indagações:

Fiquei triste, sei lá um pouco esquisita, sem saber o que pensar..., será que vou melhorar e não vai mais aparecer... (Orvalhe).

...é muito ruim, saber que tem um vírus desse dentro da gente e não poder fazer nada para acabar com ele. Dá uma sensação que a gente não é nada (Dália).

\section{Surpresa}

A surpresa é manifestada como forma de desconhecimento da existência de tal doença, e também como demonstração de impotência diante das circunstâncias causadas pela contaminação, conforme demonstrado na fala:

Fiquei surpresa, no início, um pouco chocante saber que tem um vírus desse dentro da gente que é perigoso e pode causar câncer (Bogari).

O desconhecimento da doença torna a mulher psicologicamente mais vulnerável. Apesar de muitas informações serem fornecidas durante as sessões educativas, rotineiramente realizadas por ocasião da consulta de enfermagem para realização do exame de prevenção de câncer ginecológico - bem como aconselhamento em DST/ Aids, ainda há desconhecimento da doença por parte da nossa clientela. Este fato nos leva a refletir sobre a metodologia que empregamos nas consultas de enfermagem, no que concerne à Educação em Saúde.

Estudos recentes demonstram que as mulheres têm mais informações sobre a infecção pelo Papilomavírus Humano do que os homens, e revela ainda que são os profissionais de saúde que repassam as orientações sobre as DST/Aids ${ }^{(10)}$.

\section{Traição, culpa e raiva}

Sentir raiva do parceiro quando descobre que está contaminada é um sentimento relatado com frequiência. Ao ter conhecimento de que o HPV é uma doença de transmissão sexual, a mulher que quase sempre desconfia da fidelidade do marido vê sua suspeita se confirmar. A raiva é também expressa através da rejeição. O marido, nessa fase da descoberta, a faz lembrar a infidelidade, o sofrimento e a desilusão. 
Esses sentimentos foram relatados no estudo ${ }^{(11)}$, que traduz como consequiências do HPV para o relacionamento conjugal a desconfiança, a inculpação e o afastamento do casal. Estar com HPV interfere no relacionamento de ambos, sobretudo porque produz um conflito advindo da questão "quem contaminou quem". A mulher que afirma sua fidelidade passa a conviver com a desconfiança. A culpa aponta para uma mulher duplamente vítima, quando culpa o marido e quando ele devolve a culpa para ela.

Me senti traída, usada, já desconfiava que meu marido me traia, mas depois que peguei ele com outra senti nojo... (Flor-de-Lis).

Senti culpa, raiva de mim, medo de estar com outras doenças, e ter pegado isso do meu parceiro(Violeta).

Atualmente o que têm mais chamado atenção em mulheres com HPV durante as consultas subseqüentes para a erradicação das lesões é que sua preocupação não é somente com o impacto que o HPV pode ter em sua saúde ou em sua sexualidade, mas também com as repercussões do vírus no relacionamento afetivo com seu parceiro a partir de então. Sejam estas mulheres casadas ou não, a preocupação maior está no fato de elas sentirem-se traídas por seus parceiros, por eles terem sido infiéis ${ }^{(1)}$.

Estudos $^{(12)}$ referem que as DST/Aids podem repercutir com complicações emocionais como crises pessoais e/ou conjugais, angustias e depressão.

Como conseqüência disto, surgem os sentimentos de abandono, vergonha e culpa por haver pecado ${ }^{(13)}$.

\section{Indiferença diante do resultado}

Este sentimento é atribuído a uma forma também de desconhecimento da doença ou à não-assimilação adequada do valor atribuído a esse vírus no momento do diagnóstico.

Apesar das recentes estatísticas revelarem que 1/3 da população feminina sexualmente ativa é portadora da papiloma-virose humana, a doença ainda é desconhecida da maioria das mulheres e da sociedade como um todo.

A abreviatura HPV passou nos últimos meses a fazer parte de alguns meios de comunicação, por se tratar de causador de doença em apresentadores famosos nacionalmente. Entre o anonimato e a fama, o destaque serviu para alerta à população para a prevenção. As respostas a seguir relatam tais questionamentos:

Na verdade eu não senti nada, porque naquela hora eu não me importei muito. Quando li numa revista que o HPV causou câncer na Ana Maria Braga, me lembrei que tenho esse vírus maldito e me preocupei... (Dália).
O quarto questionamento demonstrou como o relacionamento conjugal ficou modificado após o diagnóstico da doença.

A análise frente aos aspectos interpessoais no relacionamento familiar diante do diagnóstico positivo de HPV nos levou à construção da segunda temática.

Da temática repercussões no relacionamento, emergiram as categorias: descontinuidade da relação com mudança de atitude do casal; separação; sem interferência na relação conjugal; e negação.

\section{Descontinuidade da relação com mudança de atitude do casal}

O discurso feminino é o da vítima que sofre as consequiências do comportamento do marido: o culpado e o traidor. A relação de vítima que a mulher incorpora envolve acomodação, dependência e transferência de responsabilidade.

O relacionamento do casal era muitas vezes baseado na confiança mútua, e saber que houve infidelidade provoca uma mudança na relação, estabelecendo-se a desconfiança. A mulher, por não suportar a decepção com o comportamento do marido, impõe sua decisão de colocar um terceiro elemento em sua vida sexual, o preservativo. Usar condon em todas as relações produz grandes conflitos, por essa ação ser de competência masculina.

O sofrimento físico e psicológico causado pelo HPV faz a mulher imaginar que serviu de lição para o parceiro.

A inculpação por haver adquirido a doença faz a cliente repensar suas atitudes diante dos fatos, e requer mudança de comportamento. Essa mudança pressupõe um acordo entre os parceiros, trazendo à tona a culpa e as insinuações.

A diminuição da atividade sexual é outra conseqüência de conviver com o HPV. Embora a mulher acentue que reduzir a frequiência das relações sexuais seja mais difícil para o homem, ela se sente incomodada por tal fato lhe abalar profundamente a auto-estima, sobretudo por achar que seu casamento será ameaçado quando deixar de atendê-lo em suas demandas.

Mudou muito, a questão da confiança, ele pulou a cerca, do jeito que pegou HPV poderia ter pegado AIDS. A questão da fidelidade por um ato impensado dele, já pensou se eu estivesse pegado AIDS, o que seria de mim e do meus filhos, ele só pensou nele (Camélia).

Ficou meio estranho, não sabia como esconder que foi eu que pegou essa doença. Confio muito, nele e sei que ele nunca me traiu, mas joguei a culpa toda nele. Ficamos brigados e depois de alguns dias ele me disse que me amava e que se a doutora disse que tinha outras 
formas de contaminação, podia ser que ele pegou de outro jeito, então fiquei com remorso e fizemos as pazes (Girassol).

As reações emocionais à descoberta das DST podem produzir disfunções sexuais decorrentes do rompimento de relações afetivas consideradas estáveis por mágoa de um dos parceiros, ocasionada pela desconfiança ou convicção de ter sido iludido ou traído pelo companheiro infectado ${ }^{(14)}$.

\section{Separação}

Partilhar as incertezas, inseguranças e principalmente a infidelidade é correr o risco de ter uma sucessão de sofrimento, fazendo com que a mulher, diante do orgulho ferido, valorize seu ego através da separação.

Acabou, saíde casa, fui para casa da minha mãe, tenho nojo dele até hoje,... (Antúrio).

O meu antigo namorado, acho que foi ele que me transmitiu, disse para ele, ele foi no médico fez tratamento e ficou bom das verrugas, mas não brigamos..., mas acho que isso acabou nos separando sem querer, eu não consegui sentir mais tesão por ele e acho que ele também não, fiquei com vergonha dele (Narciso).

A infidelidade pode ser perturbadora, desorientadora e, conseqüentemente, a mais capaz de destruir a relação, que não seja necessariamente por causa do sexo, mas por causa do segredo e das mentiras que o envolvem ${ }^{(1)}$.

\section{Sem interferência na relação}

Mesmo vivendo os momentos de incerteza com muita intensidade, a consciência de amadurecimento da relação também está presente na vida do casal portador de HPV. As falas seguintes expressam essa realidade:

Ficou normal ninguém acusou ninguém (Bogari).

Tá do jeito que era, não tive nada, acho que ele pegou de mim, porque já tive outra pessoa antes dele. Não se,i pode ser, sei lá mas tá tudo bem (Rosa vermelha).

\section{Negação}

Muitas vezes, o casal escolhe conviver com o estigma da doença, optando por não expor os ferimentos causados pela descoberta da patologia evitando assim os comentários, as insinuações, as críticas e até as opiniões e preservando a sua união.
..., quando ele foi ao médico tive outra surpresa ele não tinha nada, e nos ficamos bem, fizemos as pazes, e hoje ninguém fala mais nisso (Girassol).

Ficou evidente que o diagnóstico do HPV interferiu prioritariamente nos sentimentos de cada um dos parceiros e no relacionamento conjugal.

\section{CONSIDERAÇÕES FINAIS}

O presente estudo nos permite refletir que abordar as DST nos últimos anos tem sido um desafio para os profissionais de saúde.

$\mathrm{O}$ fato das mulheres portadoras de HPV mostraremse conhecedoras da doença, de sua forma de transmissão e das medidas preventivas, nos leva a deduzir que a conscientização da gravidade desta patologia tem sido responsável pela elevada demanda nos serviços de saúde em atenção primaria.

Esta realidade corrobora a idéia de que atualmente a papilomavirose humana, em decorrência da sua divulgação explícita pelos diversos meios de comunicação, integra-se aos problemas de saúde pública e torna-se motivo de preocupação, não só dos profissionais de saúde mas da população em geral.

$\mathrm{Na}$ temática relacionada às reações emocionais, observamos que todos esses sentimentos tinham características negativas e iam desde a surpresa de saber desta patologia como precursora do câncer, justificando o medo e a preocupação, até a disposição para expressões de raiva, culpa e traição, desvelando a inquietação sentida a partir do risco da infidelidade dos parceiros com quem compartilhavam sua maior intimidade - o exercício da sexualidade.

A segunda temática revela a interferência da presença do HPV no relacionamento conjugal, com relatos de mudança de atitude do casal levando a descontinuidade da relação, a não aceitação da doença e a separação.

Os depoimentos descritos neste estudo nos levam a refletir sobre o sofrimento das mulheres portadoras do HPV, principalmente as mulheres nordestinas, inseridas em um contexto sócio, econômico e cultural onde os sentimentos são pouco valorizados e o preconceito e a descriminação são exacerbados.

Fica a certeza de que os esforços no sentido de quebrar a cadeia de transmissão do HPV apenas se iniciam. Muito há de se fazer para alcançar uma mudança de comportamento social que garanta o exercício de uma sexualidade segura - conquista desejada pelos profissionais de saúde que trabalham com esta temática. 


\section{REFERÊNCIAS}

1. Jacyntho C. Infecção pelo HPV e lesões pré-neoplásicas genitais: investigação laboratorial. Femina 1999; 27(9):681-5.

2. Anais do $1^{\circ}$ Consenso Brasileiro de HPV; 1999; São Roque (SP). São Paulo: BC Cultural; 2000.

3. Hatch KD, Hacker NF. Doença intra: epitelial do colo, vagina e vulva. In: Berek JS. Novak tratado de ginecologia. $12^{\mathrm{a}}$ ed. Rio de Janeiro: Guanabara Koogan; 1999.

4. Secretaria de Saúde do Estado do Ceará. Infecção subclínica pelo HPV: 1995/2002. Fortaleza; 2002.

5. Gil AC. Métodos e técnicas de pesquisa social. São Paulo: Atlas; 1999.

6. Minayo MCS. O desafio do conhecimento: pesquisa qualitativa em saúde. $4^{\mathrm{a}}$ ed. São Paulo: Hucitec; 2004.

7. Bardin L. Análise de conteúdo. Lisboa : Edições 70; 1977.

8. Brandão ML, Vianna DM, Masson S, Santos J. Organização neural de diferentes tipos de medo e suas implicações na ansiedade. Rev Bras Psiquiatr 2003; 25(2):36-41.
9. Lima JP, Lima JCP. A doença como crise na biografia do homem: um enfoque gastroenterológico. Momentos Perspec Saúde 1987; $1(2): 35-41$.

10. Holcomb Bailey JM, Crawford K, Ruffin MT. Adults' knowledge and behaviors related to human papilomavírus infection. J Am Board Fam Pract 2004; 17(1):26-31.

11. Pereira FMM. Foi ele quem procurou: um estudo sobre mulheres portadoras de papilomavirose humana (HPV). [dissertação mestrado]. Fortaleza (CE): Programa de Pós-Graduação em Saúde Pública, Universidade Estadual do Ceará; 1998.

12. Oriá MOB, Alves MDS. Adolescente com papiloma vírus humano no contexto familiar. Rev Enferm UERJ 2004; 12(1):44-8

13. Freud S. Além do principio do prazer. Rio de Janeiro: Imago; 1920.

14. Passos MRL. Fatores que interferem na prevenção de DST/ Aids. J Bras DST 2000; 11(3):3-20. 